\title{
ASSOCIATION BETWEEN JOB STRESS AND JOB SATISFACTION AMONG PHYSICIANS IN BANHA MAJOR HOSPITALS, KALIOBIA GOVERNORATE
}

\author{
By \\ ${ }^{1}$ Hassan OM and ${ }^{2} \mathrm{Abd}-$ Elmaksoud SF \\ ${ }^{1}$ Department of Community Medicine and Occupational Health, \\ ${ }^{2}$ Department of Neuro-Psychiatry, Faculty of Medicine, Benha University.
}

\begin{abstract}
:
Introduction: The issue of job stress and job satisfaction is of almost importance to the public health community and working people. Physicians cope with the cure of patients and directly confront severe illness and death. Therefore, compared with other professions, physicians experienced even heavier occupational stress and lower job satisfaction. Increasing evidence suggests that physician distress can lead to erosion of physician compassion, patient compliance and the quality of care which the physicians deliver. Aim of work: to determine levels and sources of job-related stress and job satisfaction among physicians at Banha hospitals, to identify some factors associated with both job stress and job satisfaction among physicians such as socio demographic factors, some habits and lifestyle and occupational characteristics and to investigate the association between job stress and job satisfaction. Materials and Methods: A cross-sectional study was conducted among physicians in different departments at Banha three major hospitals. Self-administered anonymous questionnaires about job related stress and job satisfaction, was used. In addition, some questions about sociodemographic characteristics, some habits and lifestyle and occupational characteristics were added. Results: The percentage of studied physicians with high total job stress score was $26.2 \%$ while percentage of those with low total job satisfaction score was $51.5 \%$. The mean total stress score was 47.2. The higher mean stress factors' scores was overload disruption to home. The mean total satisfaction score was 37.8. The higher mean satisfaction factors' scores was feeling well managed and resourced. There were two significant predictors (physical activity and specialty) out of the variables for total stress score and there was no significant predictor among general factors for total satisfaction score. Conclusion: Egyptian physicians experienced heavier occupational stress and lower job satisfaction. Our results call for paying more attention to improve physicians' job satisfaction in Egypt, to meet needed higher standards in health care.
\end{abstract} Keywords: job stress, job satisfaction, physician, Banha , satisfaction score. 


\section{Introduction}

Stress is "the reaction people may have when presented with demands and pressures that are not matched to their knowledge and abilities and which challenge their ability to cope." The stress can be either positive, friendly stress (Eustress) or negative, harmful stress (Distress). What someone perceives as a threat or a danger, someone else can perceive it as a challenge or motivation (Kerrien et al., 2015)

Job stress is a substantial and growing concern for workers, their advocates, employers, occupational health and safety regulators, and workers' compensation programs (Nakao, 2010).

Job stress is rapidly emerging as the single greatest cause of workrelated disease and injury, globally stress-related conditions is expected to rise over this decade such that by 2020, depression and anxiety disorders, including stress-related health conditions, will be second only to ischemic heart disease in prevalence. The epidemiological evidence indicates that job stress is rapidly emerging as the single greatest cause of work-related disease and injury (Magnavita and Fileni 2014).

Health sector as a whole and health professionals as a group are at higher risk of suffering from conditions related to stress. The national health services is reported as being the most, or one of the most, stressful occupation (Mengistu and Bali 2015).

Occupational stress has been a long-standing concern of the health care workers. Studies indicate that health care workers have higher rates of substance abuse and suicide than other professions and elevated rates of depression and anxiety linked to job stress. In addition to psychological distress, other outcomes of job stress include burnout, absenteeism, employee intent to leave, reduced patient satisfaction, diagnosis and treatment errors. In the USA, for example, stressed workers incur health care costs twice as high than for other employees (NIOSH, 2015).

Different studies about levels of job stress among physicians, showing variable percentages. For example the level of high job stress and being not satisfied among Canadian gynecologic and oncologist was $26 \%$ and $8 \%$ respectively (Elit et al., 2004). 
Job satisfaction is 'a pleasurable or positive emotional state resulting from the appraisal of one's job or job experiences', and it is an important issue in every work environment, but its importance is significantly higher in the field of medicine as medicine is involved with critical decisions regarding one's health (Uncuet al., 2007).

Job satisfaction has been identified as an important determinant of employee retention, turnover and work performance. In health service sectors, job satisfaction is highly associated with staff's intention to quit, quality and efficiency of services, and patient satisfaction. It has been reported that doctors with higher job satisfaction are more likely to provide more satisfactory services and produce better therapeutic effect than those with the lower one. Therefore, higher job satisfaction tends to result in much higher patient satisfaction and reduce medical costs, thereby making a hospital more competitive (Liu et al., 2010).

Rapid change process, recently experienced in all sectors and particularly in health service and policies area, had brought job dissatisfactions of health workers. In addition, negative working conditions and work burden increased and relations and environment become corrupted and size of risks had increased (Ramazen, 2008).

A study conducted in 2004 in Kuwait showed that job dissatisfaction among physicians was $38.2 \%$ ( AlEisa et al.). Another study conducted in Egypt, about job satisfaction among physicians reported that $57 \%$ of them were not satisfied (Abdel-Rahman et al., 2008).

Minimal previous studies were conducted in Egypt to reveal the magnitude of job related stress and satisfaction among the physicians.

This study was conducted in Banha City which is the capital of Kalyobia governorate. Banha City has three major hospitals with large number of overloaded physicians. The results of the study will help to reveal the suspected causes of stress in work place of them and formulate recommendations for better job satisfaction.

\section{Aim of work}

to determine levels and sources of job-related stress and job satisfaction among physicians at Banha hospitals, to identify some factors associated with 
both job stress and job satisfaction among physicians such as socio demographic factors, some habits and lifestyle and occupational characteristics and to investigate the association between job stress and job satisfaction.

\section{Materials and Methods}

\section{Technical Design:}

\subsection{Study Design:}

This study is a cross-sectional study.

\subsection{Study Setting:}

The study was conducted at the 3 main hospitals (University, educational and insurance hospitals) in Banha City, in 2013 for 3 months period.

\subsection{Target Population:}

All physicians working under the 3 hospitals' administrations were targeted. 1.4 Sampling Design:

\subsubsection{Sampling Techniques}

A list of all physicians in the three hospitals was generated. All physicians, working under the administrations of those hospitals and available during the period of study, were intended to be the sample of the study. Five hundred and fifty questionnaires were distributed among all physicians in the three hospitals after obtaining the verbal consent. All the participants were wellinformed about the contents and the aim of the questionnaire.

\subsubsection{Sample Size}

The available sample during study period was 550 physicians. The response rate was $64.2 \%$ (353 out of 550). The questionnaires with any missing item in job stress assessment or job satisfaction assessment were excluded. Therefore, the final number dropped to 281 physicians (51.1\%).

\subsection{Data Collection:}

Self-administered anonymous questionnaire was used. The questionnaire contains 5 sections; socio-demographic data, habits and life style, occupational data, assessment of job stress and assessment of job satisfaction.

The socio-demographic data includes age, gender, marital status, living with family or not and education level.

The habits and life style questions include smoking status (nonsmoker and ex-smoker/current smoker(GuitérrezBedmar et al., 2009), physical activity for at least 30 minutes per day during the 
last 7 days and watching TV; including duration of watching TV.

Occupational data includes the specialty (non-surgical and surgical), job title, total years of experience, number of working hours per week and number of night shifts per week. The Surgical specialty includes general surgery, vascular surgery, orthopedic and trauma, ear, nose and throat, ophthalmology, pediatric surgery and obstetrics and gynecology according to types of surgical specialties of Royal College of Surgeons of England. On the other hand, non-surgical specialty includes the different subspecialties of internal medicine, pediatric, medical intensive care unit, anesthesia, radiology and emergency.

The cut-off point of 40 was chosen for working hours per week because the hospital physicians at Banha are working 35 to 40 hours per week in addition to on-call duties. Moreover, studies showed that working more than 40 hours in a week, was associated with a statistically significant increase in the risk of making an error due to fatigue among health care provider in the hospitals.
The physical activity was classified according to adherence of physicians to the physical activity guidelines for Americans (2008) of $\geq 2$ hours and 30 minutes a week of moderate-intensity.

On the other hand, due to variability of average hours of watching TV among adults, the classification of hours of watching TV was done according to classification of a study about watching TV and obesity in US (Respo et al., 2001).

Modified version of the Hospital Consultant's Job stress and Satisfaction Questionnaire (HCJSSQ) was used to measure scores of total job stress and satisfaction validity and reliability of the questionnaire were tested by Cancer Research UK London Psychosocial Group (Teasdale et al., 2008).

Job Stress and job satisfaction items were aggregated as follow Job Stress factors/ subscales/ sources include:

1. Overload disruption to home (7 items).

2. Feeling poorly managed and resourced (7 items).

3. Dealing with blame and anger from patients and relatives (3 items).

4. Dealing with change in clinical practice (3 items). 
5. Encountering difficulties in relationships with staff/colleagues (3 items).

6. Dealing with patients' suffering (2 items).

7. Having managerial responsibilities (3 items).

Individual items/ sources of job stress (not aggregated under factors) include:

1. Feeling you are poorly paid for the job you do.

2. Being responsibility for the quality of the work of other staff.

3. Having unrealistic or unattainable performance targets

4. Increasingly bureaucratic and regulatory procedures

5. Having to undergo job plan and performance appraisal.

6. Disruption of your home life as a result of being on-call

7. Providing routine clinical services outside normal hours

Job Satisfaction factors/ subscales/ sources include:

1. Feeling well managed and resourced (4 items)
2. Having good relationships with patients, relatives and staff ( 3 items)

3. Having professional status/esteem (4 items)

4. Deriving intellectual satisfaction (4 items)

Individual items/ sources of job satisfaction (not aggregated under factors) include:

1. Having variety in your job.

2. Deriving intellectual stimulating from teaching.

3. Having the opportunity to practice medicine

4. Providing care within multidisciplinary teams

5. Completing a difficult clinical procedure successfully

6. Feeling you have a high level of job security.

7. Having good relationships with other staff members

The physicians were requested to rate each item of stress and satisfaction based on the extent the item contributed to any stress they have experienced in their job in the past six months. The rating of stress and satisfaction items 
ranges from 0-3"Not at all = 0", "A little $=1 "$, "Quite a bit =2" and "A lot =3".

\section{Pilot test:}

The questionnaire was pre tested on a sample of 20 physicians from the target population of the study. Those interviewed were not excluded from the main study since no major modification was added to the questionnaire. The pre-testing was done in one of the study hospitals. Pre-testing of the questionnaire was useful in estimating the time taken to answer the questions and understanding of the questions.

\section{Statistical Analysis:}

- Data was analyzed using SPSS version 16

- Descriptive statistics of sociodemographic, habits and lifestyle, occupational data and job stress and job satisfaction scores were done.

- Each source/ item of job stress and job satisfaction is rated according to the contribution it has made to the overall stress / satisfaction experienced at work.

\section{The scores on the questionnaire} were analyzed in the following ways:

1) Total Overall Scores: Overall job stress (35 items) and job satisfaction scores (22items) were calculated for by summing ratings given to each item. Total job stress and job satisfaction scores were analyzed as continuous data.

2) Factor/subscale/sources scores: Stress and satisfaction factors scores were also calculated by aggregating the ratings for the individual items within that factor. Some items from the total job stress and job satisfaction assessment were loaded and aggregated under certain factor or subscale while not aggregated items of total scores were dealt with as independent ones. Factor/subscale scores were analyzed as continuous data.

- Kolmogrov-Smirnov test was applied on the data to test for normal distribution.

- The total score of both job stress and job satisfaction was divided into low, moderate and high according to scores below 50th percentile, above 50th to 75th percentile and equal to or above 75 th percentile respectively.

\section{For total stress score:}

- Low $<48$, 
- Moderate 48 to $<60$

- And high $\geq 60$

\section{For total satisfaction score:}

- Low $<38$,

- Moderate 38 to $<46$

- High $\geq 46$.

- The data were parametric (normally distributed); therefore, parametric tests were applied.

- Pearson's coefficient correlation was used to illustrate the correlation of the total stress score with total satisfaction score.

- Multiple linear regressions analysis was used to predict factors affecting total scores of both stress and satisfaction such as sociodemographic factors, life style and habits, occupational factors and factors of stress and satisfaction.

- Probability value of $<0.05$ was considered to be statistically significant.

\section{2 -Administrative Design}

\section{- Communication}

Communication was done with the different authorities to get their permission for carrying out the field work
- Personnel

The field work was entirely carried out by the researchers

\section{- Administrative Consideration}

- Approval from the headquarter of the 3 hospitals had been taken

\section{- Ethical Consideration}

- Verbal consent was obtained from all the participants

- Cover letter from the hospital administration, explaining the study purpose and encouraging the participation was included in the questionnaire.

- Confidentiality of the data was maintained throughout the study

\section{3-Operational Design:}

3.1 Preparatory Phase: This phase included the following activities

- Searching in the scientific data base to choose the point of research.

- Literature review searching pub med, Medline and medical journals.

- Designing the methodology.

\subsection{Pilot test}

- Before conduction of the main study, a pilot test was done 


\section{Results}

About $53 \%$ of physicians were males. Regarding the age, $58.9 \%$ were $\leq$ 40 years of age, $23.2 \%$ were between $>$ $40-<50$ years and $17.9 \%$ were $\geq 50$ years of age. The majority were married $(83 \%)$ and $94.6 \%$ of the physicians were living with their families. Concerning the educational level, $44.4 \%$ of the physicians have master degree while $30.5 \%$ of them have MD or equivalent.

According to the life style and habits of the hospitals "physicians, most of them were nonsmokers $(88.4 \%)$. The current smokers were $5.7 \%$ of the total physicians involved in this study. Nearly $17.1 \%$ were not physically active (for at least 60 minutes per day during the last 7 days). Fifty two percent were physically active for 4-7 days and $31 \%$ were physically active for 1-3 days during last 7 days as regards watching TV on average day, $44.1 \%$ of physicians watch TV for less than an hour per day,
$33.5 \%$ watches TV for an hour to less than 5 hours and $21 \%$ don't watch TV on average day.

The occupational data of the hospitals' physicians involved in the study, physicians with non-surgical specialty were $66.9 \%$. Around $65.3 \%$ were specialists, $21.1 \%$ were senior or principle house officer and $12.6 \%$ were consultants.

Concerning the total years of experience; $24.6 \%$ of physicians had experience of $\geq 20$ years whereas $75.5 \%$ had experience of less than 20 years. Most of the physicians were working more than 40 hours per week $(81.9 \%)$ and $66.1 \%$ had two or more night shifts per week .Around $26.2 \%$ of physicians had high job stress score while $51.1 \%$ had low one according the levels of total stress score and around $51.5 \%$ of physicians had low job satisfaction score while $26.4 \%$ had high one according the levels of total satisfaction score. 
Table (1): Scores of total stress and stress factors among Banha hospitals' physicians $(\mathbf{N}=\mathbf{2 8 1})$

\begin{tabular}{|c|c|c|c|c|}
\hline \multirow[t]{2}{*}{ Domains/Sources of job stress } & \multirow[t]{2}{*}{ Mean } & \multirow{2}{*}{$\begin{array}{l}\text { Std. } \\
\text { Deviation }\end{array}$} & \multicolumn{2}{|c|}{$\begin{array}{l}95 \% \text { confidence } \\
\text { Interval }\end{array}$} \\
\hline & & & Lower & Upper \\
\hline Factor 1: Overload disruption to home life & 10.66 & 4.758 & 10.17 & 11.18 \\
\hline $\begin{array}{l}\text { Factor2: Feeling poorly managed and } \\
\text { resourced. }\end{array}$ & 8.481 & 4.003 & 8.04 & 8.29 \\
\hline $\begin{array}{l}\text { Factor3: Dealing with blame and anger } \\
\text { from patients and relatives. }\end{array}$ & 3.913 & 2.076 & 3.69 & 4.13 \\
\hline $\begin{array}{l}\text { Factor 4: Dealing with change in clinical } \\
\text { practice }\end{array}$ & 4.163 & 2.015 & 3.95 & 4.38 \\
\hline $\begin{array}{l}\text { Factor 5: Encountering difficulties in } \\
\text { relationships with staff/colleagues }\end{array}$ & 2.172 & 1.811 & 1.98 & 2.36 \\
\hline Factor 6: Dealing with patients' suffering & 3.391 & 1.689 & 3.21 & 3.57 \\
\hline Factor 7: Having managerial responsibilities & 3.805 & 2.232 & 3.57 & 4.04 \\
\hline Total Stress Score & 47.216 & 17.633 & 45.15 & 49.28 \\
\hline
\end{tabular}

Table (1) shows that the mean total stress score was 47.2 with standard deviation of $17.6(n=281)$. Overload disruption to home life $(10.7 \pm 4.8)$, was the higher mean stress factors' scores.

Table (2): Scores of total satisfaction and satisfaction factors among Banha hospitals> physicians $(\mathbf{N}=\mathbf{2 8 1})$

\begin{tabular}{|l|c|c|c|c|}
\hline \multicolumn{1}{|c|}{ Domains/Sources of job satisfaction } & \multirow{2}{*}{ Mean } & $\begin{array}{c}\text { Std. } \\
\text { Deviation }\end{array}$ & \multicolumn{2}{c|}{$\begin{array}{c}\text { 95\% confidence } \\
\text { Interval }\end{array}$} \\
\cline { 4 - 5 } & & & Lower & Upper \\
\hline Factor1: Feeling well managed and resourced & 6.444 & 2.601 & 6.16 & 6.72 \\
\hline $\begin{array}{l}\text { Factor 2: Having good relationships with } \\
\text { patients, relatives and staff }\end{array}$ & 6.466 & 2.000 & 6.25 & 6.68 \\
\hline Factor 3: Having professional status / esteem & 6.915 & 2.483 & 6.64 & 7.19 \\
\hline Factor 4: Deriving intellectual satisfaction & 6.494 & 2.684 & 6.20 & 6.78 \\
\hline Total Satisfaction Score & 37.750 & 10.979 & 36.46 & 39.04 \\
\hline
\end{tabular}

Table (2) illustrates that the mean total satisfaction score was 37.8 and feeling well managed and resourced $(6.44 \pm 2.6)$ was the higher satisfaction factors' scores. 
Table (3): Correlation of total stress score with total satisfaction score Banha Hospitals> physicians.

\begin{tabular}{|c|c|c|}
\hline \multirow{2}{*}{ Scores } & \multicolumn{2}{|c|}{ Total Satisfaction Score } \\
\hline \multirow{3}{*}{ Total Stress Score } & Pearson Correlation & Sig. (2-tailed) \\
\cline { 2 - 3 } & 0.094 & 0.144 \\
\cline { 2 - 3 } & $\mathrm{N}$ & 281 \\
\hline
\end{tabular}

Table (3) shows that there is no correlation of the total stress score with total satisfaction score. Pearson correlation coefficient was (0.094).

Table (4): Results of multiple linear regressions of general factors affecting the total score of stress among Banha hospitals> physicians.

\begin{tabular}{|l|c|c|c|c|c|c|c|}
\hline \multirow{2}{*}{$\begin{array}{c}\text { Independent } \\
\text { variable }\end{array}$} & \multicolumn{2}{c|}{$\begin{array}{c}\text { Unstandardized } \\
\text { Coefficients }\end{array}$} & $\begin{array}{c}\text { Standardized } \\
\text { Coefficients }\end{array}$ & \multirow{2}{*}{$\mathbf{t}$} & \multirow{2}{*}{ Sig. } & \multicolumn{2}{c|}{$\begin{array}{c}\text { 95\% Confidence } \\
\text { Interval for B }\end{array}$} \\
\cline { 2 - 5 } & $\mathbf{B}$ & $\begin{array}{c}\text { Std. } \\
\text { Error }\end{array}$ & Beta & & $\begin{array}{c}\text { Lower } \\
\text { Bound }\end{array}$ & $\begin{array}{c}\text { Upper } \\
\text { Bound }\end{array}$ \\
\hline (Constant) & 51.65 & 14.49 & & 3.56 & 0.00 & 23.097 & 80.199 \\
\hline Age & -0.07 & 0.42 & -0.04 & -0.17 & 0.86 & -0.901 & 0.755 \\
\hline Gender & -1.597 & 2.598 & -0.05 & -0.62 & 0.54 & -6.715 & 3.522 \\
\hline Marital Status & 3.302 & 3.558 & 0.07 & 0.928 & 0.35 & -3.706 & 10.310 \\
\hline Education level & -3.485 & 2.324 & -0.145 & -1.50 & 0.14 & -8.063 & 1.093 \\
\hline Smoking & 0.271 & 3.451 & 0.005 & 0.078 & 0.94 & -6.528 & 7.070 \\
\hline Physical activity & -4.439 & 1.546 & -0.185 & -2.872 & $0.004 *$ & -7.484 & -1.394 \\
\hline Watching TV & -0.640 & 1.530 & -0.027 & -0.419 & 0.676 & -3.655 & 2.374 \\
\hline Specialty & 6.951 & 2.373 & 0.183 & 2.929 & $0.004 *$ & 2.275 & 11.626 \\
\hline Job title & 3.255 & 3.235 & 0.108 & 1.006 & 0.315 & -3.118 & 9.628 \\
\hline $\begin{array}{l}\text { Total years of } \\
\text { experience }\end{array}$ & 0.051 & 0.407 & 0.025 & 0.126 & 0.900 & -0.751 & 0.853 \\
\hline $\begin{array}{l}\text { Number of work } \\
\text { hours per week }\end{array}$ & 2.427 & 2.961 & 0.053 & 0.820 & 0.413 & -3.405 & 8.260 \\
\hline $\begin{array}{l}\text { Number of night } \\
\text { shifts per week }\end{array}$ & 1.491 & 1.344 & 0.075 & 1.109 & 0.269 & -1.158 & 4.139 \\
\hline a Dependent Variable : Total Stress Score & & & & & \\
\hline
\end{tabular}

*: Significant

Table (4) shows that there were two statistically significant predictors (physical activity and specialty) out of the variables for total stress score. 
Table (5): Results of multiple linear regressions of general factors affecting the total score of satisfaction among Banha hospitals> physicians.

\begin{tabular}{|l|c|c|c|c|c|c|c|}
\hline \multirow{2}{*}{$\begin{array}{c}\text { Independent } \\
\text { variable }\end{array}$} & \multicolumn{2}{|c|}{$\begin{array}{c}\text { Unstandardized } \\
\text { Coefficients }\end{array}$} & $\begin{array}{c}\text { Standardized } \\
\text { Coefficients }\end{array}$ & \multirow{2}{*}{ t } & \multirow{2}{*}{ Sig. } & \multicolumn{2}{|c|}{$\begin{array}{c}\text { 95\% Confidence } \\
\text { Interval for B }\end{array}$} \\
\cline { 2 - 5 } & B & $\begin{array}{c}\text { Std. } \\
\text { Error }\end{array}$ & Beta & & & $\begin{array}{c}\text { Lower } \\
\text { Bound }\end{array}$ & $\begin{array}{c}\text { Upper } \\
\text { Bound }\end{array}$ \\
\hline (Constant) & 24.324 & 9.255 & & 2.628 & 0.009 & 6.092 & 42.557 \\
\hline Age & 0.252 & 0.272 & 0.199 & 0.927 & 0.355 & -0.284 & 0.789 \\
\hline Gender & -1.084 & 1.604 & -0.049 & -0.676 & 0.500 & -4.243 & 2.075 \\
\hline Marital Status & -0.669 & 2.162 & -0.022 & -0.309 & 0.757 & -4.928 & 3.591 \\
\hline Education level & -0.239 & 1.502 & -0.016 & -0.159 & 0.874 & -3.199 & 2.720 \\
\hline Smoking & 0.683 & 2.306 & 0.019 & 0.296 & 0.767 & -3.860 & 5.226 \\
\hline Physical activity & 1.261 & 0.973 & 0.086 & 1.295 & 0.197 & -0.657 & 3.178 \\
\hline Watching TV & 0.305 & 0.958 & 0.021 & 0.318 & 0.750 & -1.583 & 2.193 \\
\hline Specialty & 2.731 & 1.501 & 0.115 & 1.819 & 0.070 & -0.227 & 5.689 \\
\hline Job title & 1.821 & 2.069 & 0.097 & 0.880 & 0.380 & -2.256 & 5.898 \\
\hline $\begin{array}{l}\text { Total years of } \\
\text { experience }\end{array}$ & 0.050 & 0.260 & 0.039 & 0.191 & 0.849 & -0.462 & 0.562 \\
\hline $\begin{array}{l}\text { Number of work } \\
\text { hours per week }\end{array}$ & -1.133 & 1.889 & -0.040 & -0.600 & 0.549 & -4.855 & 2.589 \\
\hline $\begin{array}{l}\text { Number of night } \\
\text { shifts per week }\end{array}$ & 1.680 & 0.858 & 0.135 & 1.958 & 0.051 & -0.010 & 3.370 \\
\hline a Dependent Variable : Total Stress Score & & & & & \\
\hline
\end{tabular}

Table (5) reveals that there was no significant predictor of total stress score among satisfaction factors and items. 


\section{Discussion}

The percentage of studied physicians with high total job stress score was $26.2 \%$ while percentage of those with low total job satisfaction score was $51.5 \%$. The result of job stress among physicians was similar to many studies as (Elit et al., 2004) who conducted a cross-sectional survey on a group of Canadian gynecologic oncologists and they found that approximately $26 \%$ of physicians are experiencing high stress, and this is strongly associated with emotional exhaustion and high depersonalization. Fourteen percent of Canadian gynecologic oncologists are actively looking for alternative jobs and $45 \%$ are trying to decrease the number of hours worked per week.

Furthermore, a study conducted in Egypt (Abdel-Rahman et al. ,2008), about job satisfaction among physicians reported that $57 \%$ of them were not satisfied while a study conducted on Norwegian doctors showed that 50\% of the sample studied was not satisfied with their jobs (Madaan 2008).Also our findings were consistent with that of Kumar et al. (2013) in Pakistan, where $59 \%$ of the study participants were dissatisfied with their job. Our work is also in agreement with a study conducted in Al-Madinah Al-Munawwara, where overt job dissatisfaction among physicians and nursing staffs were $67.1 \%$ and $52.4 \%$ respectively.

Mengistu and Bali (2015) found that the majority of health workers were dissatisfied with their job , only $34.9 \%$ of the study participants were satisfied with their job, while nearly two third $(65.1 \%)$ were dissatisfied with their job.

Concerning total job stress score predictors, the current study revealed that physical activity (exercise) was a significant predictor. More than $80 \%$ of the physicians in this study were found to practice exercise during last 7 days. Moreover, being more physically active was significantly associated with lower stress among studied physicians. Evidence revealed that engaging in a physically active lifestyle is important for personal reasons. That proposition is based on the substantive evidence linking employee physical activity to a wide range of positive individual outcomes at work, such as greater productivity, reduced chronic stress responses (e.g., absenteeism, turnover) and greater job satisfaction (Reston, 2010). 
Similar finding was found in a study was done on 12 physicians, 12 one-hour aerobic sessions were administered for 2 or 3 days weekly to reach the required level of weekly energy expenditure of $17.5 \mathrm{kcal} / \mathrm{kg}$ measured by a calories counter. This was found to significantly reduce the participants' emotional exhaustion and their degree of depersonalization to a lesser extent. However, no significant change was observed with regard to their sense of personal accomplishment ( Gerber et al 2013 )

Shanafelt et al 2010 also studied the personal health habits and wellness practices among US surgeons and found that physicians who participated in aerobic and muscle-strengthening exercises according to CDC guidelines had high quality of life scores. Surgeons who placed an emphasis on finding meaning in work, focusing on what is important in life, maintained a positive outlook, and embraced a balanced work/ life were less likely to get burned out .

In the current study, having good relationships with patients, relatives and staff was not a significant predictor of stress among the studied physicians. Three important sets of relationships have been identified: relationships with superiors, relationships with subordinates and relationships with colleagues; have been highlighted as potential stressors. It has been argued strongly that good relationships amongst workers and members of work groups are essential for both individual and organizational health.

According to literature, in health care organization many factors are very essential: optimal work arrangement; the possibility to participate actively in decision making process; effective communication among staff and supervisors and to be able to express freely one's (OpinionKaarna, 2007).

In this study, having professional status/esteem and deriving intellectual satisfaction are the commonest sources of job satisfaction among physicians (53\%). Many studies revealed that job autonomy may be a strong motivating force leading to greater satisfaction. Analyses revealed that physicians who spent part of their time involved with research activities were more likely to report favorable job characteristics ratings. Physicians involved with research were also more likely to be satisfied with their job (David and 
James, 2011). The same finding was found in a study conducted by Alsaqabi et al 2010 on sixty physicians working in the department of internal medicine to determine the level of job satisfaction among doctors working at AL-Sabah Hospital in Kuwait and identify aspects of dissatisfaction and factors that could be associated with. They found that $60 \%$ of physician in their study were satisfied with their autonomy.

A study about psychosocial stress among hospital doctors in surgical fields was conducted in Germany. About onefifth of the hospital doctors in surgical specialties surveyed had thought about giving up their profession several times a month or more frequently (Knesebeck et al., 2010). In the current study, moving to another hospital, changing job, having health problems, quitting job and having poor relationships with coworkers were all reported as consequences of job stress by the physicians. About $29.4 \%$ of physicians were thinking to change the hospital due to job stress which may reflect also their dissatisfaction and suggest further investigation and action.

Five sources of job stress; overload disruption to home life, feeling poorly managed and resourced and dealing with patients' suffering, having managerial responsibilities, having to submit a job plan and undergo performance appraisal and being required to provide routine clinical services (outpatient clinics) outside working hours were significant predictors of dissatisfaction among studied physicians hospitals.

Studies that have investigated job stress and job satisfaction have generally found an inverse relationship between several job stressors and job satisfaction. The medical profession is a challenging but stressful profession. Work pressures, consistently linked to job stress among physicians, include heavy workloads, time 'on-call', fatigue, conflicts between work and personal lives, and dealing with patient problems, among others (Huda et al., 2004).

Nevertheless, in this study, no correlation was found between total stress score and total satisfaction score. The results might indicate that sources of job stress are not necessarily related to sources of job satisfaction among physicians. In an earlier study, leka and Jain. (2010) examined the 
relationship between consultants' ( $n=882$ specialist doctors) mental health and their job stress and satisfaction. Findings indicated that job satisfaction significantly protected consultants' mental health against job stress. Three sources of stress were found: feeling overloaded, and its effect on home life; feeling poorly managed and resourced; and dealing with patients' suffering, were associated with both burnout and psychiatric morbidity.

Work-life conflicts have been found to be significantly associated with workload in a number of studies. Due to the high workload in many physicians' jobs, such as long working hours, long working days, high job demands and high emotional demands, physicians are expected to be a risk group for work-life conflicts and consequently for health problems. Therefore, several international studies have analyzed work-life conflicts among physicians. A study analyzing German hospital physicians compared the results with non-physicians, showed that worklife conflicts among physicians are significantly stronger than in the general German population (Knechta et al., 2010).
In summary, job related stress and satisfaction are important issue for health care workers especially physicians. Many factors are contributing to job stress and dissatisfaction. Further studies are recommended to explore the etiology and consequences and to suggest the interventions.

\section{Limitations:}

The study is cross-sectional in nature so we cannot conclude causes of high job stress or low job satisfaction from this study. In addition, the selfreported data might raise the issue of self-reported response bias.

\section{Conclusion:}

Egyptian physicians experienced heavier occupational stress and lower job satisfaction. Our results call for paying more attention to improve physicians' job satisfaction in Egypt, to meet needed higher standards in health care.

\section{Recommendations:}

The causes of job stress among junior physicians should be elaborated in further studies including the importance of training and personal development,aspects of job stressors associated with surgical specialty 
should be addressed including the impact on personal and family life. To reduce job stress among physicians, measures should be undertaken to improve the structural conditions within the departments and involve the physicians in stress relieving activities.

The impact of the job stress of physicians on quality of care, outcome variables and personal effect should be studied in depth and further studies should include other health care sectors and health care workers for better understanding of stress and dissatisfaction sources and for comparison.

\section{References}

1. Abdel-Rahman AG, abdel Halim AW, Allam MF and Meky F ( 2008 ): Low Job Satisfaction among Physicians in Egypt. TSK Koruyucu Hekimlik Bülteni ; 7 (2): 91-96.

2. Abdullah M A and Kishk NA (2006): Job Satisfaction among Primary Health Care Physicians and Nurses in Al-Madinah AlMunawwara. Journal of Egyptian Public Health Association ; 81 (3\& 4).

3. Al-Eisa IS, Al Mutar MS and Al-Abdul jalil HK (2005): Job Satisfaction of Primary Health Care Physicians at Capital Health Region, Kuwait. Middle East Journal of Family Medicine; 3 (3).

4. Alsaqabi F, Aldousari A, Ismail AE and El-Shazly M (2010): Job Satisfaction Among Physicians In Al-Sabah Hospital, Kuwait .Alexandria Journal of Medicine; 46 (2).
5. CDC\& NIOSH (2014): Exposure to Stress: Occupational Hazards in Hospitals. Department of Health and Human Services centers for Disease Control and Prevention National Institute. DHHS (NIOSH). Accessed on $12 / 02 / 2014$

6. Crespo CJ, Smit E, Troiano RP, Bartlett SJ, Macera CA and Andersen RE (2001): Television Watching, Energy Intake, and Obesity in US Children Results From the Third National Health and Nutrition Examination Survey, 1988-1994. Arch Pediatr Adolesc Med; 155:360-365 .

7. David M and James B (2011): Job Characteristics and Job Satisfaction Among Physicians Involved With Research in the Veterans Health Administration. Academic Medicine: Journal of Association of American Medical Colleges; 86 (8): 938-945.

8. Elit L, Trim K, Mand-Bains IH, Sussman J and Grunfeld E (2004): Job satisfaction, stress and burnout among Canadian gynecologic oncologist. Gynecologic Oncology; 94 (1): 134-139.

9. Gerber M, Brand S, Elliot C, Holsboer-Trachsler E, Pühse U and Beck J (2013): Aerobic exercise training and burnout: a pilot study with male participants suffering from burnout. BMC Res Notes; 6:78. [PMC free article] [PubMed]

10. Grant P ( 2004): Physician job satisfaction in New Zealand versus United Kingdom. Journal of the New Zealand Medical Association; 117 (1204)

11. Guitérrez-Bedmar C, Seguí-Gómez M, GómezGracia E, Bes-Rastrollo $M$ and MartínezGonzález M ( 2009) :Smoking Status, Changes in Smoking Status and Health Related Quality of Life: Findings from the SUN ("Seguimien Universidad de Navarra"). Int. J. Environ. Res. Public Health; 6: 310-320.

12. Huda B, Rusli B, Naing L, Tengku M, Winn T and Rampal K (2004): A study of Job Strain and Dissatisfaction among Lecturers in the School 
of Medical Sciences University Sains Malaysia. Southeast Asian. J Trop Med Public Health; 35 (1) $: 38$.

13. Kaarna M (2007): The importance of job satisfaction in hospital quality process. Nordic School of Public Health.http://www.nhv.se/ upload/dokument/forskning/ Publikationer/ MPH/2007/MPH20 07-4_Marina_Kaarna.pdf

14. Kerrien M, Pougnet R, Garlantézec R, Pougnet L, Le Galudec M, Loddé B and Dewitte JD ( 2015) :Prevalence of anxiety disorders and depression among junior doctors and their links with their work. Presse Med.2015 Jan 29. pii: S0755-4982(14)00643-5

15. Knechta M,Bauera G,KlaghoferbR,BuddebergFischerb B, Stammb $M$ and Hämmiga $\mathrm{O}$ ( 2010): Work-life conflicts and health among Swiss physicians - in comparison with other university graduates and with the general Swiss working population. The European Journal of Medical Science. Swiss Medical Weekly

16. Leka S and Jain A (2010): Health Impact of Psychosocial Hazards at Work: An Overview. Institute of Work, Health \& Organizations, University of Nottingham. WHO 2010.

17. Liu J, Wang Q and Lu Z (2010): Job satisfaction and its modeling among township health center employees: a quantitative study in poor rural China. BMC Health Services Research 2010, 10:115 http://www.biomedcentral.com/1472$6963 / 10 / 115$

18. Madaan N (2008) :Job Satisfaction among Doctors in a Tertiary Care Teaching Hospital. JK Science; 10 (2).

19. Magnavita N and Fileni A (2014):Work stress and metabolic syndrome in radiologists: first evidence. Radiol Med. Feb; 119(2):142-8. doi: 10.1007/s11547-013-0329-0. Epub 2013 Dec 3.

20. Mengistu MM and BaliAG (2015): Factors Associated to Job Satisfaction Among Health care Workers at Public Hospitals of West Shoa Zone, Oromia Science Journal of Public Health; 3(2): 161-167

21. Nakao M (2010)Work-related stress and psychosomatic medicine. Bio Psycho Social Medicine, 4:4. Available at: http://www. bpsmedicine.com/content/4/1/4

22. Ramazen E, Rahman S, Avci L, Gokta B, Enoolu I and Firat G (2008): Investigating Job Satisfaction and Burnout Levels of the Persons Working for the Hospitals at City Center of Elazi $\square$ Turkey. Journal of Applied Sciences Research; 4(2): 188201.

23. Ramesh K, Jamil A, Babar S, Rehan H and Assad H (2013): Job satisfaction among public health professionals working in public sector: a cross sectional study from Pakistan. BMC Human Resources for Health; 11:2.

24. Reston V ( 2010) :A Philosophical Position on Physical Activity \& Fitness for Physical Activity Professionals. National Association for Sport and Physical Education, 80.

25. Shanafelt TD, Balch CM, Bechamps G, Russel T, Dyrbye L, Satele D, et al.( 2010) : Burnout and medical errors among American surgeons. Ann Surg; 251:995-1000. [PubMed]

26. Teasdale E, Drew S, Taylor C and Ramirez A (2008): Hospital Consultants' Job Stress \& Satisfaction Questionnaire (HCJSSQ): User Manual. Cancer Research UK London Psychosocial Group .

27. U.S. Department of Health and Human Services. Physical Activity Guidelines for Americans 2008. Available at: http://www.health.gov/ PAGuidelines

28. Uncu Y, Baryam N and Bilgel N (2007): Job related affective well-being among primary health care physicians. European Journal of Public Health; 17 (5): 514-519. 